\title{
Radiofrequency Ablation versus Partial Splenic Artery Embolization in Hypersplenism
}

\author{
MONA O. ABOELEZZ, M.D.*; ESSAM MOHAMED HEMMAT, M.D.*; IBRAHIM M.M. ELADL, M.Sc.* and \\ MAHMOUD ABDO ASHOUR, M.D.** \\ The Departments of Radio Diagnosis* and Internal Medicine**, Faculty of Medicine, Zagazig University, Egypt
}

\begin{abstract}
Background: Radiofrequency Ablation (RFA) has undergone tremendous progress with the advances in modern technologies because of its minimal invasiveness, good tolerance, and rapid recovery more than Partial Splenic Artery embolization (PSE) in treatment of hypersplenism.
\end{abstract}

Aim: The aim of the study was to correlate results from RFA and PSE with clinical and laboratory findings in patients with hypersplenism.

Subjects and Methods: This study was carried out at Radio-Diagnosis Department, Zagazig University Hospitals during the period from October 2015 to July 2018, included 34 patients, 17 patients subjected to RFA, and the other 17 patients subjected to partial PSE. All patients were subjected to complete clinical examination, laboratory investigations Post procedure follow-up after 2 weeks, then every 1 month in the first 3 months and every 3 months during the 1 year.

Results: Both techniques increased the hemoglobin, leucocytic count, and platelets significantly in comparison with the pre-operative values in each group $(p<0.05)$. Comparing the post-operative values in both groups, comparable rise in the hemoglobin level occurred $(p<0.05)$. On the other hand, PSE group had significantly higher rise of leucocytic count and platelets than RFA group $(p<0.01)$.

Conclusion: PSE was more effective in treatment of thrombocytopenia and leucopenia, but with a significant increase in morbidity. Moreover, serious adverse events after PSE will push us to find safer techniques to avoid these losses. On the other hand, RFA had some advantages, such as easier technique, more confined lesions, and fewer complications.

Key Words: Radiofrequency ablation - Partial splenic artery embolization-Hypersplenism - Spleen.

\section{Introduction}

HYPERSPLENISM means increased destructive function of the spleen. It is characterized by cytopenia, splenomegaly, increased or normal medullar

Correspondence to: Dr. Mona O. Aboelezz, The Department of Radio Diagnosis, Faculty of Medicine, Zagazig University, Egypt cellularity and elevated turnover of the involved cellular linemay. It may lead to serious bleeding tendency due to thrombocytopenia and recurrent infections due to leucopenia. Hypersplenism is traditionally treated by surgical splenectomy. However, patients with cirrhotic splenomegaly and hypersplenism often have many other complications, which may restrict the use of splenectomy. Thus, minimally invasive approaches that mean partial splenectomy are becoming increasingly demanded [1].

Partial splenic artery embolization used as a surgical alternative to splenectomy in cases with hypersplenism especially patients who are poor candidates for surgery [2] .

Hematologic response correlates with the amount of the infarcted splenic tissue after partial splenic embolization. Almost all of the interventionists attempt to achieve infarction between $50 \%$ and $70 \%$ of the splenic mass to get good therapeutic hematologic response and alleviate hypersplenism

Thermal ablative treatment ablates part of the spleen parenchyma that means partial splenectomy through which the syndrome of hypersplenism can be relieved. It has been shown that preservation of at least $25 \%$ of the splenic parenchyma ensures an adequate short-and long-term splenic function [4]. Radiofrequency (RF) ablation has undergone tremendous progress with the advances in modern technologies. Radiofrequency ablation has attracted widespread attention because of its minimal invasiveness, good tolerance, rapid recovery, shorter hospitalization, and significant clinical outcome and relatively low cost [5].

Potential benefits of radiofrequency ablation include reduced morbidity and mortality in com- 
parison with standard surgical resection and the ability to treat patients who are not suitable for conventional surgical resection [6].

\section{Subjects and Methods}

\section{Patients:}

This study is a randomized clinical trial study. The study was approved by the Local Ethical Committee. It was carried out at Radio-Diagnosis Department, Zagazig University Hospitals, during the period from October 2015 to July 2018. A total of 34 patients were included in this study. Patients were classified into two main groups, 17 cases were subjected to radiofrequency ablation (12) males and (5) females, their ages ranged from 37 to 65 years (mean age $\pm \mathrm{SD}$ is $46.88 \pm 6.52$ years), and 17 cases were subjected to partial splenic artery embolization (13) males and (4) females, their ages ranged from 39 to 63 years (mean age \pm SD is $47.94 \pm 6.58$ years).

\section{Inclusion criteria:}

All patients with the criteria of hypersplenism:

1- Thrombocytopenia with or without leucopenia.

2- Either splenomegaly or normal sized spleen.

3- Normo-cellular or hyper-cellular bone marrow.

\section{Exclusion criteria:}

1- Patients with hypocellular or infiltrative bone marrow disease.

2- Patients with known collagen vascular or autoimmune disorders.

3- Patients with ischemic heart disease, renal failure or malignant disease.

4- Patients with suspected unavailability throughout the study.

5- Psychiatric illnesses and substance abuse (alcohol addict).

\section{All patients were subjected to the following:}

A- Full clinical history: Personal history (name, age, sex), present history of main clinical presentation and past history of bleeding tendency or episodes of hematemesis and/or melena.

B- Complete clinical examination to evaluate the state of spleen, liver, ascites, collaterals.

C- Laboratory investigations including: Complete blood picture (Hb, RBCs, WBCs and platelets), Liver function tests (SGOT, SGPT, albumin and bilirubin), Serum creatinine, Coagulation profile (PT, PTT and INR), Hepatitis B Surface Antigen (HBsAg) and anti-Hepatitis C Virus (HCV) and Bone marrow aspiration biopsy.
D- Radiological investigations including; abdominal ultrasonography to examine the size and echopattern of liver, size of spleen and presence or absence of ascites and color-coded duplex scanning of the portal circulation to verify patency of portal vein, the direction of flow and flow velocity post-operative.

\section{Partial splenic artery embolization protocol:}

A- Patients were advised to fast for at least 6 hours for solids and 4 hours for fluids before the procedure and enema was done for all patients in the night before embolization.

B- Intravenous line was established and the patients were well hydrated (because of the potential need for large volume of contrast medium).

C- Antibiotics were used one day pre-operatively $(50-100 \mathrm{mg} / \mathrm{kg} /$ day) and for 5 days after embolization.

D- The intended puncture site (inguinal region) was shaved immediately before the procedure in the Radiology Unit (in order to reduce the superficial skin irritation with infection caused by shaving in the previous day).

\section{E- Embolization techniques:}

- On the angiography table, patients were asked to lie in a supine position, in a comfortable position that can be tolerated for the duration of the procedure. A sterile puncture site preparation (iodinated scrub) was done. Local anesthesia was infused with $10 \mathrm{ml}$ of $2 \%$ xylocaine (lidocaine hydrochloride $20 \mathrm{mg} / \mathrm{ml}$ ) at the site of puncture.

- The entry site is the site where right common femoral artery pulsation was well felt.

- Small skin incision turned into completed; the puncture become finished the usage of a Seldinger needle ( 18 gauge $=$ Zero. 042 inch) angled parallel to the course of the femoral artery; about forty five stages with the skin. Once a terrific pulsatile blood again thru the needle, the stylet changed into eliminated and a terumo instantly guide wire ( 0.032 inch) turned into lightly advanced up to lower abdominal aorta underneath fluoroscopic steerage. The needle become eliminated, a five $\mathrm{F}$ sheath $(5 \mathrm{~F})$ inserted along the manual wire and fixed in region. The location of the sheath inside the femoral artery was confirmed with the aid of saline injection and blood aspiration. A five cobra head catheter was advanced (sometimes, a 2.5-Fr microcatheter) along the guide wire through the femoral artery into the abdominal aorta, selective catheterization of the celiac axis and splenic artery was performed. 
- A preliminary splenic angiogram was obtained to determine the configuration of splenic artery and location of its pancreatic branches. The catheter was then advanced forward, if possible, so that its tip lays distal to the last major pancreatic branch to minimize the risk of pancreatitis, or better in one of the polar branches of the splenic artery Fig. (2).

- After being sure that the catheter within the splenic artery or one of its polar branches using fluoroscopic guidance, the guide wire was removed and the embolic agent was gently injected through the catheter using free flow technique. The injection of embolic material was done very slowly to avoid its reflux. foam.

- The embolic agent used in this study was gel

- During embolization, small amount of contrast material was periodically injected through the catheter to monitor the flow distribution within the spleen. After completing embolization splenic angiography was performed to confirm reduction of approximately $60-70 \%$ of splenic blood flow Fig. (3).

- After that, the catheter was irrigated by saline and removed.

- Compression was done over the site of puncture for about 10-15 minutes. Then, the site of puncture was covered and patients were asked to extend their legs and maintain bed rest for the rest of the day of procedure.

- After the procedure, the site of puncture was observed every 15 minutes for 4 hours then every 30 minutes for 4 hours then every 4 hours for 16 hours to detect bleeding or hematoma as early as possible.

\section{2- Radiofrequency ablation protocol:}

A- Patients had a normal prothrombin time and simple hypersplenism, and no history or serious risk of esophageal variceal bleeding, underwent percutaneous RFA. Informed consent was obtained from all patients after discussion of the benefits and risks of the procedure.

B- Patients were advised to fast for at least 6 hours for solids and 4 hours for fluids before the procedure and enema was done for all patients in the night before embolization.

C- Vital signs were closely monitored for evidence of intra-abdominal haemorrhage. An LDRF50CA RFA system (Lead Electron Corporation, Mianyang, China) was used in all patients. Before procedure, the number and position of RFA needles were determined according to the shape and volume of the spleen. At most, three needles were used simultaneously. To avoid thermal injury to surrounding organs and decrease post-operative complications (particularly left pleural effusion), the middle and lower parts of the spleen were selected for ablation. RFA needles were inserted under ultrasound guidance perpendicularly $3-5 \mathrm{~cm}$ into the spleen, away from the capsule and hilar vessels Fig. (1). Power was set initially at $50 \mathrm{~W}$, increased by $10 \mathrm{~W}$ every $2 \mathrm{~min}$ to a maximum of $95 \mathrm{~W}$, and then maintained until the impedance reached a maximum value. Energy deposition was terminated automatically, completing the ablation cycle. The electrodes were withdrawn by $1-2 \mathrm{~cm}$ for the next session. Because steam produced in this procedure interfered with observation, the needles were placed in different positions in the spleen. After treatment, electrode needles were withdrawn slowly with the radiofrequency generator set at $95 \mathrm{~W}$ to cauterizes the needle route and decrease post-operative bleeding. Antibiotic prophylaxis was administered for 3-5 days after the procedure.

\section{III- Postprocedural assessment:}

A- Bed rest one day after the procedure.

B- Observation of puncture site and vital signs.

C- High fluid intake is important.

D- IV antibiotic (1gm coefoperazone 112 hours) was continued for 5 days to decrease the risk of splenic abscess.

E- Analgesia was given (in the form of non-steroidal anti-inflammatory) not only for the patient's comfort but also to reduce the risk of complications, as abdominal pain may impair breathing motion, which may in turn leads to atelectasis and pneumonia.

F- Serum amylase measurement was done 24 hours after embolization to exclude hyperamylasemia and/or pancreatitis.

G- Chest radiographs were obtained as indicated to exclude the possibility of pneumonia or pleural effusion.

\section{IV- Follow-up:}

- Post procedure follow-up US before discharge, after two weeks to look for evidence of splenic abscess and then every 1 month in the first 3 months and every 3 months during the 1 year follow-up.

- Platelet count 2 weeks after the procedure.

- Follow-up every 1 month in the first 3 months and every 3 months during the 1 year follow-up period in outpatient clinic, a follow-up platelet count will be done and revised. 
- All hospital admissions occurring at any time after randomization will be recorded and data collected on length of stay, any further procedures, and adverse events.

\section{Statistical analysis:}

Analysis of data was done using SPSS Version (SPSS Version 25) (Statistical Package for the Social Sciences) (IBM, 2017).

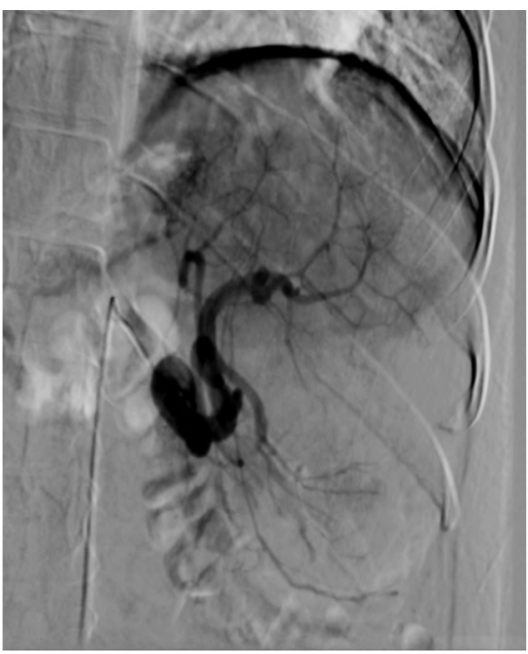

Fig. (2A): Contrast injection in the distal huge splenic artery showing all the branches.

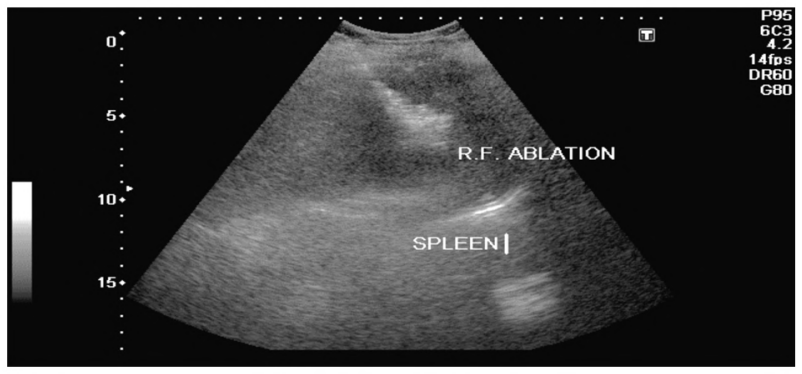

Fig. (1): Radio frequency ablation.

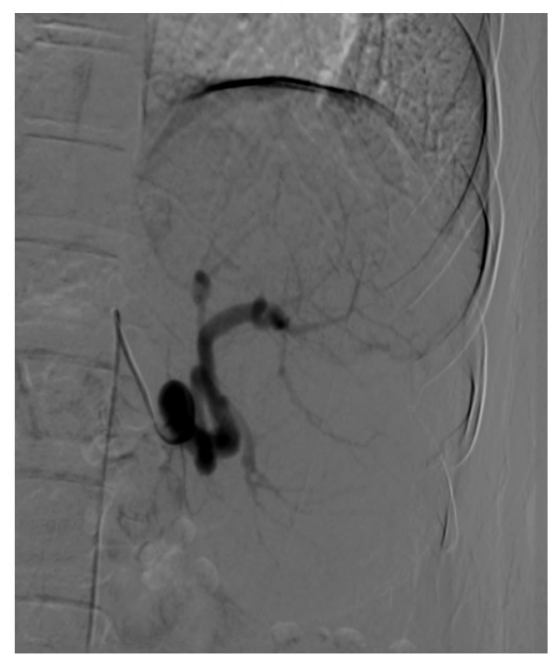

Fig. (2B): Contrast injection in the huge splenic artery after embolization of $\sim 50 \%$ of its branches and reflux of injection.

Fig. (2): Partial distal splenic embolization.
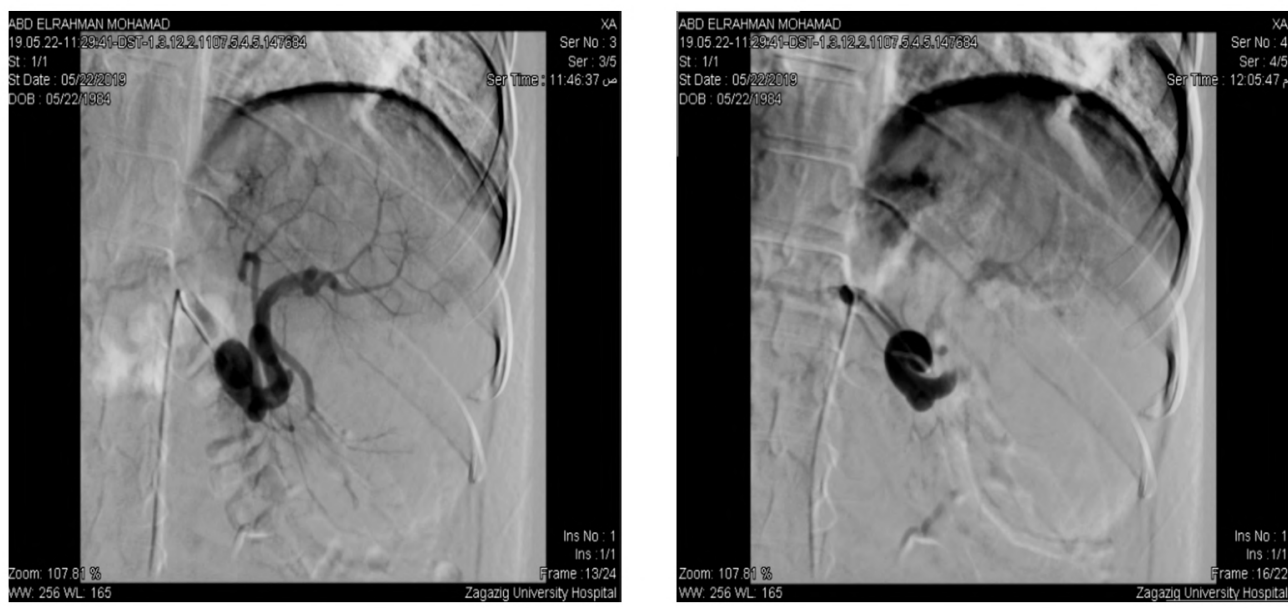

Fig. (3): Partial splenic embolization.

\section{Results}

A total of 34 patients were included in this study. Patients were classified into two main groups, 17 cases were subjected to radiofrequency ablation and 17 cases were subjected to partial splenic artery embolization.

Both groups were matching regarding the age (Table 1) and sex (Table 2). From (Table 3), marked splenomegaly is more than mild and moderate splenomegaly among the patients. Pre-operatively, both groups have comparable bone marrow findings (Table 4) as well as INR levels (Table 5).

Table (1): Age distribution of study participants.

\begin{tabular}{lcccc}
\hline Age/years & Group (A) & Group (B) & $t$-test & $p$-value \\
\hline Mean \pm SD & $46.88 \pm 6.52$ & $47.94 \pm 6.58$ & 0.471 & 0.641 \\
Range & $37-65$ years & $39-63$ years & & \\
\hline
\end{tabular}


Table (2): Sex distribution of study participants.

\begin{tabular}{lcccccccc}
\hline \multirow{2}{*}{ Sex } & \multicolumn{2}{c}{ Group (A) } & & \multicolumn{2}{c}{ Group (B) } & & $\chi^{2}$ & $\begin{array}{c}p- \\
\text { value }\end{array}$ \\
\cline { 2 - 3 } & No. & $\%$ & & No. & $\%$ & & \\
\hline Male & 12 & 70.59 & & 13 & 76.47 & 0.697 & 1.00 \\
Female & 5 & 29.41 & 4 & 23.53 & & \\
\hline Total & 17 & 100.00 & 17 & 100.00 & & \\
\hline
\end{tabular}

Table (3): Splenic size of study participants.

\begin{tabular}{|c|c|c|c|c|c|c|}
\hline \multirow{2}{*}{$\begin{array}{l}\text { Splenic } \\
\text { size }\end{array}$} & \multicolumn{2}{|c|}{ Group (A) } & \multicolumn{2}{|c|}{ Group (B) } & \multirow{2}{*}{$\chi^{2}$} & \multirow{2}{*}{$\begin{array}{c}p- \\
\text { value }\end{array}$} \\
\hline & No. & $\%$ & No. & $\%$ & & \\
\hline Mild & 3 & 17.65 & 4 & 23.53 & 0.210 & 0.901 \\
\hline Moderate & 6 & 35.29 & 6 & 35.29 & & \\
\hline Marked & 8 & 47.06 & 7 & 41.18 & & \\
\hline Total & 17 & 100.00 & 17 & 100.00 & & \\
\hline
\end{tabular}

Table (4): Bone marrow of study participants.

\begin{tabular}{|c|c|c|c|c|c|c|}
\hline \multirow{2}{*}{ Bone marrow } & \multicolumn{2}{|c|}{ Group (A) } & \multicolumn{2}{|c|}{ Group (B) } & \multirow{2}{*}{$\chi^{2}$} & \multirow{2}{*}{$\begin{array}{c}p- \\
\text { value }\end{array}$} \\
\hline & No. & $\%$ & No. & $\%$ & & \\
\hline Normocellular & 3 & 17.65 & 2 & 11.76 & 0.628 & 1.00 \\
\hline Hypercellular & 14 & 82.35 & 15 & 88.24 & & \\
\hline Total & 17 & 100.00 & 17 & 100.00 & & \\
\hline
\end{tabular}

Table (5): INR level distribution of study participants.

\begin{tabular}{lcccc}
\hline INR & Group (A) & Group (B) & $t$-test & $p$-value \\
\hline $\begin{array}{l}\text { Mean } \pm \text { SD } \\
\text { Range }\end{array}$ & $1.23 \pm 0.09$ & $\begin{array}{l}1.20 \pm 0.08 \\
- \text { years }\end{array}$ & 1.00 & 0.325 \\
\hline
\end{tabular}

Both techniques increased the hemoglobin, leucocytic count, and platelets significantly in comparison with the pre-operative values in each group $(p<0.05)$.

Comparing the post-operative values in both groups, comparable rise in the hemoglobin level occurred $(p<0.05)$ Fig. (4).

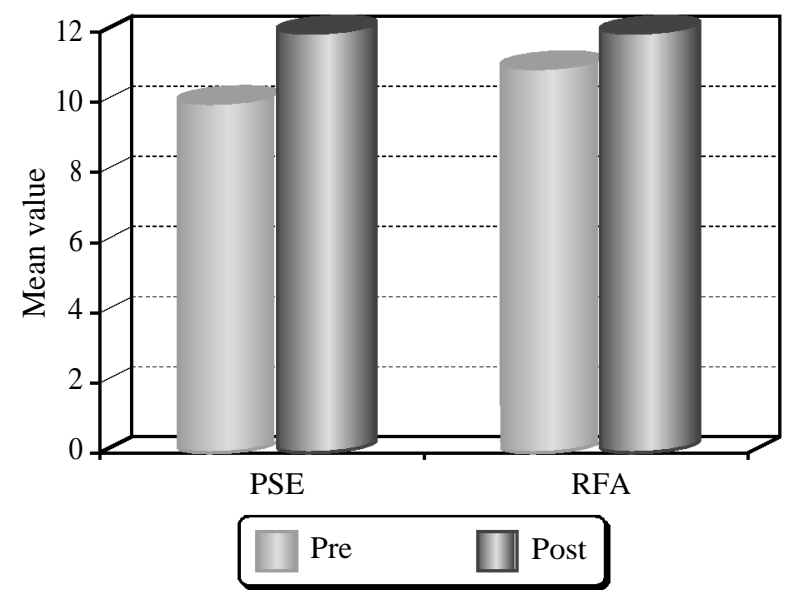

Fig. (4): Hemoglobin ratio of studied groups.
On the other hand, PSE group had significantly higher rise of leucocytic count and platelets than RFA group $(p<0.01)$ (Tables 6-8) Fig. (5).

Table (6): White blood cells count ratio of studied groups.

\begin{tabular}{|c|c|c|c|c|}
\hline WBC & PSE & RFA & $t$-test & $p$-value \\
\hline $\begin{array}{l}\text { Pre: } \\
\quad \text { Mean } \pm \text { SD }\end{array}$ & $2280.5 \pm 698.9$ & $2440 \pm 523.6$ & 1.256 & 0.352 \\
\hline $\begin{array}{l}\text { Post: } \\
\quad \text { Mean } \pm \text { SD }\end{array}$ & $16832.5 \pm 3493.2$ & $3101 \pm 372.1$ & 7.639 & 0.001 \\
\hline $\begin{array}{l}t \text {-test } \\
p \text {-value }\end{array}$ & $\begin{array}{l}9.362 \\
0.001 *\end{array}$ & $\begin{array}{l}2.632 \\
0.042 *\end{array}$ & & \\
\hline
\end{tabular}

Table (7): Hemoglobin ratio of studied groups.

\begin{tabular}{lllll}
\hline HB & \multicolumn{1}{c}{ PSE } & \multicolumn{1}{c}{ RFA } & $t$-test & $p$-value \\
\hline Pre: & & & & \\
$\quad$ Mean \pm SD & $9.02 \pm 1.69$ & $10.15 \pm 1.36$ & 0.663 & 0.529 \\
Post: & & & & \\
$\quad$ Mean \pm SD & $11.04 \pm 1.12$ & $10.95 \pm 0.69$ & 0.412 & 0.225 \\
$t$-test & 2.362 & 2.630 & & \\
$p$-value & $0.014^{*}$ & $0.030^{*}$ & & \\
\hline
\end{tabular}

Table (8): Platelets count of studied groups.

Platelets Group (A) Group (B) $\quad t$-test $\boldsymbol{p}$-value

\begin{tabular}{llll}
\hline Pre-platelet: & & & \\
$\quad$ Mean \pm SD $34.00 \pm 6.42$ & $35.12 \pm 6.79$ & 0.493 & 0.625
\end{tabular}

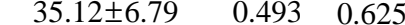

Post-platelet:

Mean \pm SD $275.82 \pm 15.55 \quad 278.82 \pm 12.00 \quad 0.630 \quad 0.533$

Post 2:

Mean \pm SD $237.94 \pm 15.73 \quad 242.35 \pm 13.39 \quad 0.881 \quad 0.385$

Post 3:

Mean \pm SD $216.06 \pm 13.38 \quad 223.29 \pm 14.72 \quad 1.50 \quad 0.143$

Post 4:

Mean \pm SD $206.47 \pm 12.49 \quad 212.53 \pm 13.28 \quad 1.370 \quad 0.180$

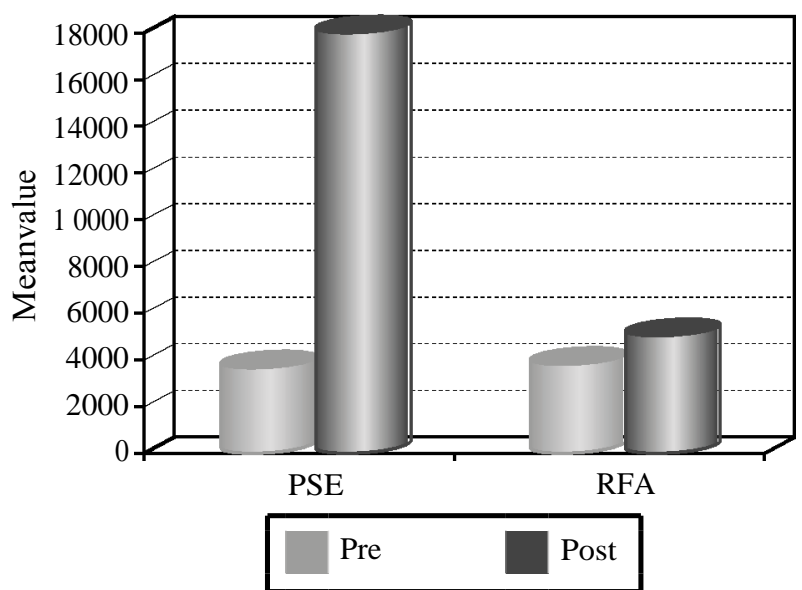

Fig. (5): White blood cells count of studied groups. 
Unfortunately, there was significant increase in post-operative complications after Partial Splenic Embolization (PSE) than radiofrequency ablation (RFA) (Table 9).

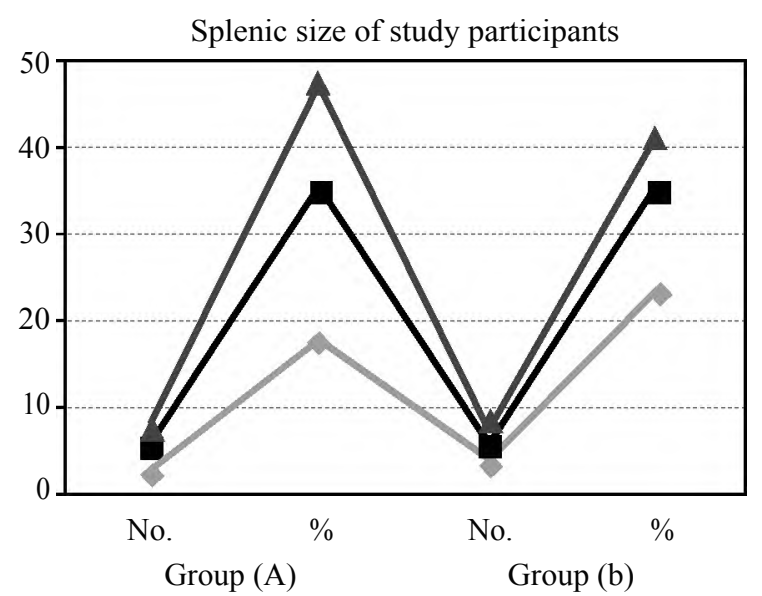

Fig. (6): Splenic size of study participants.
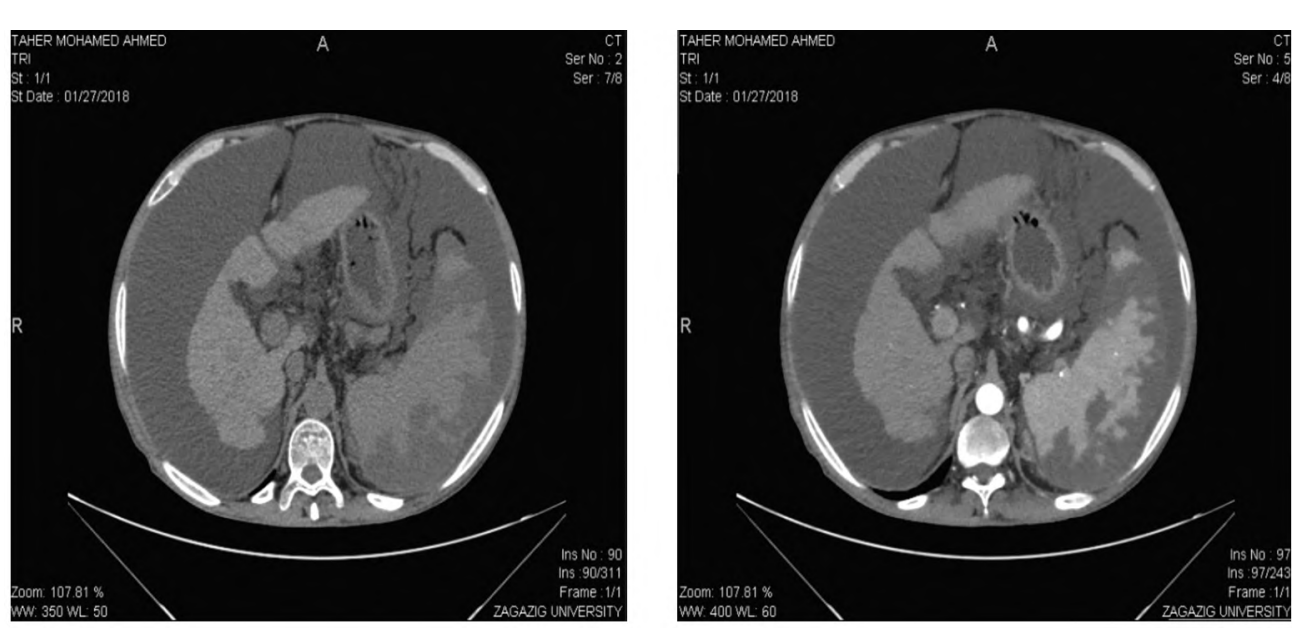

Fig. (8): Complications after PSE technique.
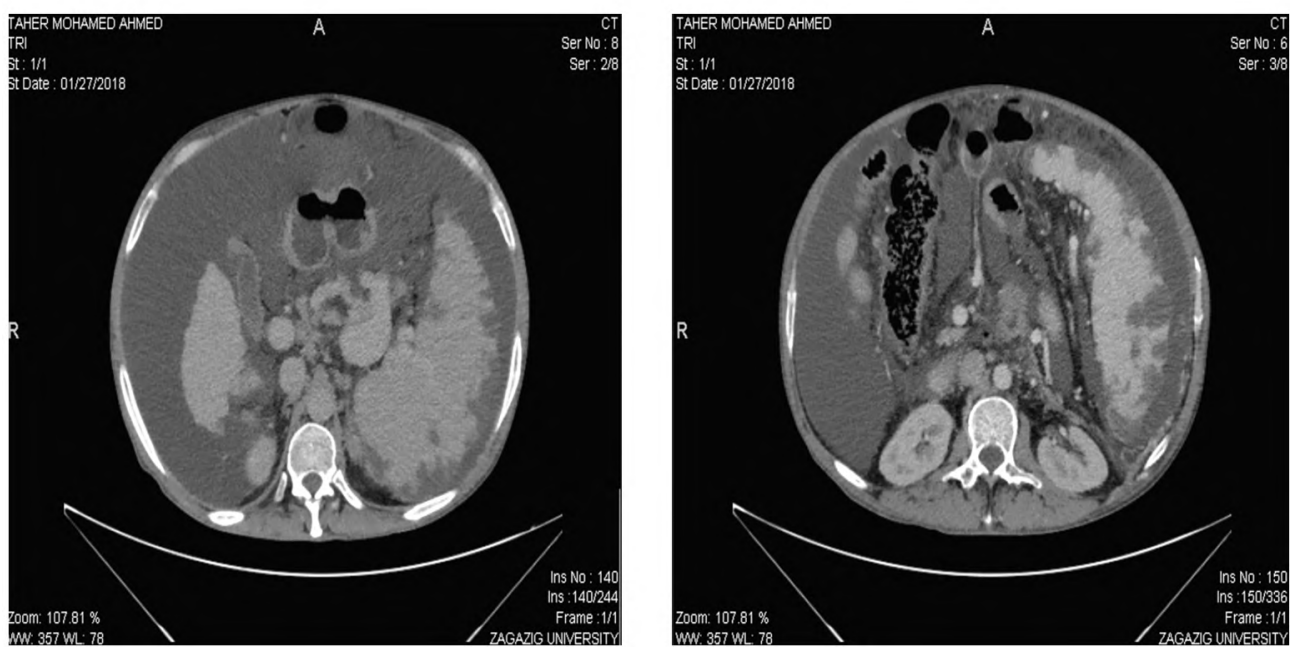

Fig. (9): Complications after PSE technique.

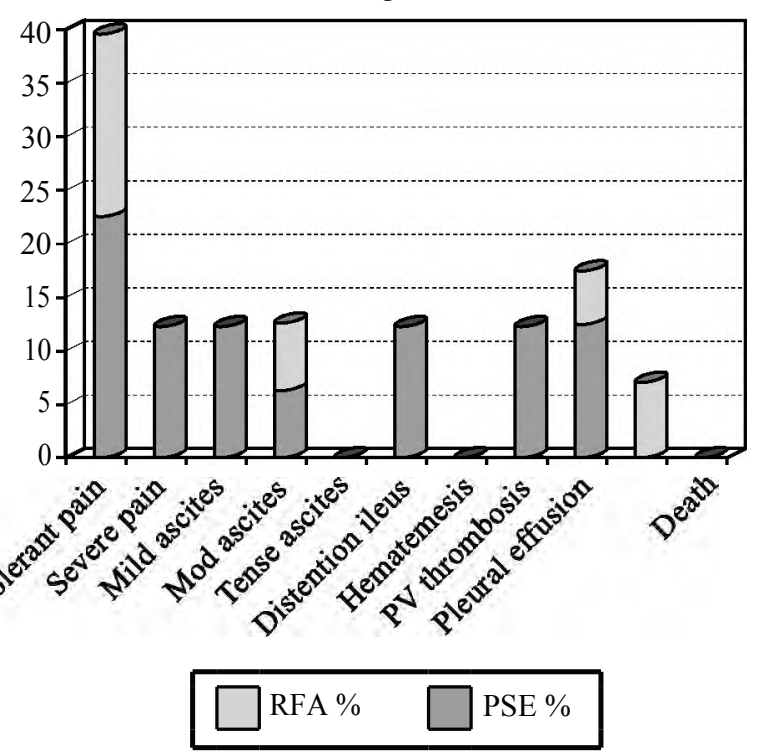

Fig. (7): Complications after treatment of studied groups. 
Table (9): Complications after treatment of studied groups.

\begin{tabular}{|c|c|c|c|c|}
\hline & \multicolumn{2}{|c|}{ PSE } & \multicolumn{2}{|c|}{ RFA } \\
\hline & $\mathrm{N}$ & $\%$ & $\mathrm{~N}$ & $\%$ \\
\hline - Tolerant pain & 4 & 23 & 3 & 17 \\
\hline - Severe pain & 2 & 12 & - & - \\
\hline - Mild ascites & 2 & 12 & & \\
\hline - Mod ascites & 1 & 6 & 1 & 6 \\
\hline - Tense ascites & & & - & - \\
\hline - Distention ileus & 2 & 12 & - & - \\
\hline • Hematemesis & & & - & - \\
\hline - PV thrombosis & 2 & 12 & & \\
\hline • Pleural effusion & 2 & 12 & 1 & 6 \\
\hline $\begin{array}{l}\text { - Iatrogenic (dysfunction of needle } \\
\rightarrow \text { presplenic hematoma }\end{array}$ & 0 & 0 & 1 & 6 \\
\hline - Death & - & - & - & - \\
\hline - Total & 17 & 100 & 17 & 100 \\
\hline - $\chi^{2}$ & & & & \\
\hline •p-value & & & & \\
\hline
\end{tabular}

\section{Discussion}

Although the clinical benefit of splenic artery embolization has been shown in many studies [7], to the best of our knowledge, our study is the first in which splenic artery embolization with radiofrequency ablation for treating patients with massive splenomegaly were compared.

RFA has received increasing attention as a tissue-sparing approach for treating malignant neoplasms. Indications are expanding rapidly to include tumours in the liver, kidney, lung, bone, breast and adrenal gland. RFA represents a novel option for treating hypersplenism. The safety and efficacy of splenic RFA have been verified in this and previous studies $[8]$.

In agreement with previous studies, splenic RFA yielded good short-term effects. Short-term effectiveness was good in all groups, but hypersplenism recurred by 6 months in patients with less than $50 \%$ of splenic ablation [9].

Some studies revealed that the platelet count increased slightly 2-4 hours after completion of splenic embolization. They attributed this to the reduction of splenic function. Secondary hypercoagulopathy and consumption of platelets caused by SAE was documented as negligible [8]

Postembolic pain is a significant abdominal discomfort after SAE. The pain following artery embolization can be categorized roughly into two mechanisms: Postembolic pain occurring immediately after embolization and pain caused by tissue infarction that occurs in the delayed phase [9].

During the first day after SAE, there was only 1 patient of their 17 patients who received $15 \mathrm{mg}$ pentazocine IV for pain [10]. In our study, there was improvement in platelet count in our patients treated with SAE.

RFA produces a more confined lesion, reducing the frequency and severity of complications. Splenic RFA rarely leads to abscess formation which may be related to the fact that it produces coagulation necrosis, as opposed to the liquefaction after embolization. RFA is convenient to perform, and requires less expensive equipment. In addition, splenic RFA preserves the immune function of the body, because a portion of the spleen is retained [11] .

We also did not have any transfusion free patients after RFA. Some studies have reported that $20 \%$ of their patients became transfusion free after partial RFA of spleen [12]. We think the difference in outcomes is the result of the smaller ablation ratio in our study $(9.83 \%)$ compared with that in their study $(32.3 \%)$. This suggests the increase in hemoglobin levels is related to the ratio of the ablated spleen. Although we found no significant correlation between the ablation ratio and hemoglobin level after RFA using Spearman's rank correlation coefficient, this lack of correlation might be due to the narrow range of the ablation ratio $(5.3 \%$ to $23.7 \%)$ or the limited number of cases in our study.

Some studies have indicated that the histology of the splenic remnant changes throughout the splenic parenchyma after RFA. The histopathological changes of splenic lesions caused by RFA include local coagulative necrosis, peripheral thrombotic infarction, and occlusion of vessels in the remaining normal splenic tissue, as well as deposition of extensive fibrous protein and disappearance of congestive splenic sinusoid, all of which seem to explain the spleen shrinkage [13] However, we found no significant change in the size of the spleen after RFA. This may be due to the fact that the ablation ratio in our study was limited to less than $10 \%$ of the total splenic volume, in contrast to studies with higher ablation ratios.

\section{Conclusion:}

PSE was more effective in treatment of thrombocytopenia and leucopenia, but with a significant increase in morbidity. Moreover, serious adverse events after PSE will push us to find safer techniques to avoid these losses. On the other hand, percutaneous minimally invasive RFA of the spleen seems to be a safe and cost-effective therapeutic technique with more confined lesions, and fewer complications. More extensive studies are still 
required to investigate the efficacy and safety of this technique.

\section{References}

1- AMIN M.A., EL-GENDY M.M., DAWOUD I.E., SHOMA A., NEGM A.M. and AMER T.A.: World J. Surg., 33 (8): 1702-10, 2009.

2- KOCONIS K.G., SINGH H. and SOARES G.: Partial splenic embolization in the treatment of patients with portal hypertension: A review of the English language literature. J. Vasc. Interv. Radiol., 18: 463-81, 2007.

3- ABDELLA H.M., ABD-EL-MOEZ A.T., ABU ELMAATY M.E. and HELMY A.Z.: Role of partial solenic embolization for hypersplenism in patients with liver cirrhosis and thrombocytopenia. Indian J. Gastroenterol. Mar., 29 (2): 59-61, 2010.

4- RASEKHI A.R., NADERIFAR M., BAGHERI M.H., et al.: Radiofrequency ablation of the spleen in patients with thalassemia intermedia: A pilot study. A.J.R. Am. J. Roentgenol., 192: 1425-9, 2009.

5- GAZELLE G.S., GOLDBERG S.N., SOLBIATI L. and LIVRAGHI T.: Tumor ablation with radio-frequency energy. Radiology, 217: 633-46, 2013.

6- LIU Q., MA K., SONG Y., ZHOU N. and HE Z.: Twoyear follow-up of splenic radiofrequency ablation in patients with cirrhotic hypersplenism: Does increased hepatic arterial flow induce liver regeneration? Surgery, 143: 509-18, 2008.
7- SWANSON T., MENEGHETTI A., SAMPATH S., et al.: Hand assisted laparoscopic splenectomy versus open splenectomy for massive splenomegaly: 20-year experience at a Canadian center. Can J. Surg., 54 (3): 189-93, 2011.

8- LIU Q., MA K., SONG Y., et al.: Two-year follow-up of splenic radiofrequency ablation in patients with cirrhotic hypersplenism: Does increased hepatic arterial flow induce liver regeneration? Surgery, 143 (4): 509-18, 2008.

9- TOMIKAWA M., AKAHOSHI T., SUGIMACHI K., et al.: Laparoscopic splenectomy may be a superior supportive intervention for cirrhotic patients with hypersplenism. J. Gastroenterol. Hepatol., 25: 397-402, 2010.

10- RESO A., BRAR M.S., CHURCH N., et al.: Outcome of laparoscopic splenectomy with preoperative splenic artery embolization for massive splenomegaly. Surg. Endosc., 24: 2008-10, 2010.

11- FENG K., MA K., LIU Q., WU Q., DONG J. and BIE P.: Randomized clinical trial of splenic radiofrequency ablation versus splenectomy for severe hypersplenism. British Journal of Surgery, 98 (3): 354-61, 2011.

12- RASEKHI A.R., NADERIFAR M., BAGHERI M.H., et al.: Radiofrequency ablation of the spleen in patients with thalassemia intermedia; a pilot study. A.J.R. Am. J. Roentgenol., 192: 1425-9, 2009.

13- LIU Q., MA K., HE Z., DING J., HUANG X. and DONG J.: Experimental study on the feasibility and safety of radiofrequency ablation for secondary splenomagely and hypersplenism. World Journal of Gastroenterology: WJG, 9 (4): 813, 2003.

\title{
التردد الحرارى مقارثة بإحداث إنسداد دموى جزئى فى شريان الطحال فى حالات فرط نشاط إحل الطحال
}

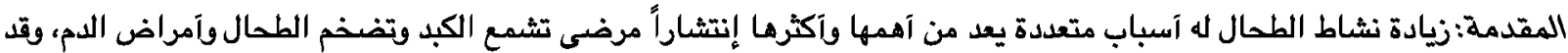

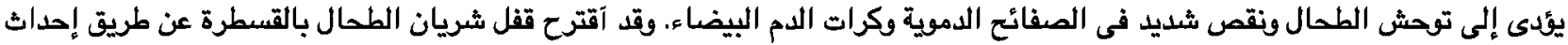

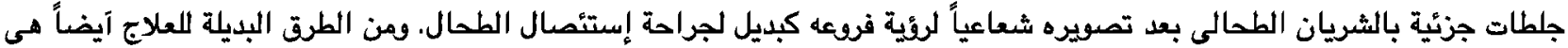

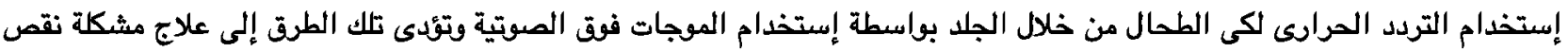

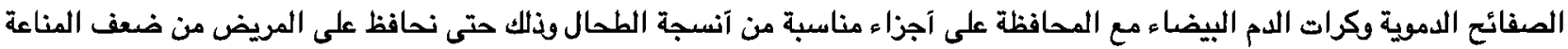 \\ وحدوث الإلتهابات الساحقة.
الهدف من البحث: يهدف البحث إلى تقييم إستخدام إحداث الجلطات الجزئية بالشريان الطحالى مقارنة بإستخدام التردد الحرارى لعلاج الطحال المكسر للدم آو المعروف بتوحش الطعال. \\ المواد وطرق البحث: آجريت هذه الدراسة بقسم الآثعة بمستشفيات جامعة الزتازيق للمرضى الذين يعانون من زيادة نشاط الطحال. \\ النتيجة:وجد آن كلا الطريقتين مؤثرة وفعالة لفرط نشاط الطحال مع حدوث زيادة في المضاعفات مع الغلق الجزئى الشريان الطحال

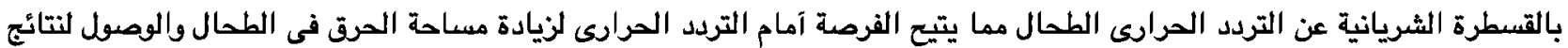

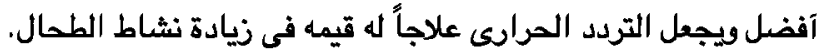

